Article

\title{
New Distance Measure for Atanassov's Intuitionistic Fuzzy Sets and Its Application in Decision Making
}

\author{
Di Ke ${ }^{1}$, Yafei Song ${ }^{2, *}$ and Wen Quan ${ }^{3}$ \\ 1 School of Business, Nankai University, Tianjin 300071, China; kedi1991@126.com \\ 2 College of Air and Missile Defense, Air Force Engineering University, Xi'an 710051, China \\ 3 College of Air Traffic Control and Navigation, Air Force Engineering University, Xi'an 710051, China; \\ quanwen@163.com \\ * Correspondence: songyafei@mail.afeu.edu.cn; Tel.: +86-029-84789154
}

Received: 5 September 2018; Accepted: 19 September 2018; Published: 22 September 2018

check for updates

\begin{abstract}
The intuitionistic fuzzy set introduced by Atanassov has greater ability in depicting and handling uncertainty. Intuitionistic fuzzy measure is an important research area of intuitionistic fuzzy set theory. Distance measure and similarity measure are two complementary concepts quantifying the difference and closeness of intuitionistic fuzzy sets. This paper addresses the definition of an effective distance measure with concise form and specific meaning for Atanassov's intuitionistic fuzzy sets (AIFSs). A new distance measure for AIFSs is defined based on a distance measure of interval values and the transformation from AIFSs to interval valued fuzzy sets. The axiomatic properties of the new distance measure are mathematically investigated. Comparative analysis based in numerical examples indicates that the new distance measure is competent to quantify the difference between AIFSs. The application of the new distance measure is also discussed. A new method for multi-attribute decision making (MADM) is developed based on the technique for order preference by similarity to an ideal solution method and the new distance measure. Numerical applications indicate that the developed MADM method can obtain reasonable preference orders. This shows that the new distance measure is effective and rational from both mathematical and practical points of view.
\end{abstract}

Keywords: Atanassov's intuitionistic fuzzy sets; distance measure; similarity measure; decision making

\section{Introduction}

The theory of fuzzy set was initiated by Zadeh [1] to handle uncertainty. In a fuzzy set, the membership degree of its element is a real number in interval [0,1]. The values of membership and non-membership are summed to 1 for every element of a fuzzy set. By loosening this constrain, Atanassov [2] developed the concept of intuitionistic fuzzy set for the better depiction on uncertainty. For an Atanassov's intuitionistic fuzzy set (AIFS), its membership degree and non-membership degree are both real numbers in [0,1], and their summation is less than 1 . The difference between 1 and their summation leads to another parameter of AIFS, namely, the hesitancy degree. Later, Gau and Buehrer [3] presented the concept of vague set. It was pointed out by Bustince and Burillo [4] that the notion of vague sets was identical to that of AIFSs. Since its inception, AIFS has attracted much attention from researchers. Research on AIFS mainly concentrates on its mathematical properties [5], intuitionistic fuzzy measures [6,7], its connection with other uncertainty theories [8,9], and its applications in practical problems under uncertainty $[9,10]$.

Similarity and distance measures of AIFSs are defined to discriminate the information conveyed by different AIFSs. The concepts of similarity and distance are complementary. They can be regarded 
as two different aspect of the discrimination measure. The similarity measure quantifies the closeness degree between AIFSs, while the measure of distance is defined to depict the difference between AIFSs. Because of the importance of similarity and distance measures in intuitionistic fuzzy theory, many researchers have been dedicated to defining reasonable similarity and distance measures for AIFSs.

Szmidt and Kacprzyk used the widely used Euclidean distance and Hamming distance to define distance measures for AIFSs [11]. Vlachos and Sergiadis [12] proposed an entropy-based distance measure for AIFSs. The definition of intuitionistic fuzzy distance measure was firstly axiomatically proposed by Wang and Xin [13]. Following the proposed axiomatic definition, they developed a new distance for AIFSs and applied it into pattern application. Li and Cheng [14] presented the axiomatic properties of similarity measure for AIFSs. They also put forward a kind of similarity measure for AIFSs and apply it in pattern recognition. Following Li and Cheng's similarity measure, Mitchell [15] modified it and developed a more general similarity measure. Liang and Shi [16] also improved Li and Cheng's similarity measure and introduced a new method to define similarity measure for AIFSs. Then, Hung and Yang [17] developed several approaches to construct similarity measure for AIFSs and applied these new proposed similarity measures to the evaluation of students' answer scripts. By providing a comprehensive review on the distance measure and similarity measure if AIFSs, $\mathrm{Xu}$ and Chen [18] presented a continuous distance and similarity measures for AIFSs. Inspired by Szmidt and Kacprzyk's method [19], Xu and Yager [20] improved the similarity measure of AIFSs and proposed an improved method to measure the similarity degree between AIFSs. By using the operators on intuitionistic fuzzy values (IFVs), Xia and Xu [21] proposed several similarity measures for IFVs, which can be generalized to similarity measures of AIFSs. Following analysis on the relation between entropy and intuitionistic fuzzy similarity measures, Wei et al. [22] introduced a new method for constructing similarity measure based on entropy measures of interval-valued fuzzy sets, which have been proved to be equivalent to AIFSs. Based on the cosine of the angle between two vectors, Ye [23] defined a cosine similarity measure for AIFSs. An intuitionistic fuzzy similarity measure was proposed by Hwang et al. [24] that was based on the Sugeno integral. On the basis of the relationship between intuitionistic fuzzy entropy and intuitionistic fuzzy similarity, Li et al. [25] defined an entropy-based similarity measure for AIFSs. Zhang and Yu [26] proposed two new distance measures for AIFSs based on interval data and triangular fuzzy numbers. Boran and Akay [27] introduced a new type of similarity measures for AIFSs depending on two parameters. By quantifying the consensus level between AIFSs, Song et al. [6,7] developed some new similarity measures. The relationship between intuitionistic fuzzy values and right-angled triangular fuzzy numbers was analyzed by Chen et al. [28], where a new similarity measure between intuitionistic fuzzy sets was introduced based on the centroid points of the transformed right-angled triangular fuzzy numbers.

In the similarity and distance measures mentioned above, these distance measures defined based on general distance metrics have weaker discrimination capability. So they may lead to counter-intuitive results in some special cases. Some derived measures have complex forms but without specific physical meaning. An effective distance measure with relative concise expression and clear physical meaning is desirable from both the mathematical and practical points of view. In this paper, we will propose a new distance measure for AIFSs based on the relation between AIFSs and interval values. Properties of the proposed distance measure will be analyzed together with proofs. We compare the proposed measure with some typical existing measures to show its effectiveness and rationality by using some numerical examples. Then the proposed distance measure is applied in multi-attribute decision making (MADM) by developing a new multi-attribute decision making method.

The rest of this paper is organized as follows. In Section 2, some basic knowledge on AIFSs is presented. Section 3 presents a review on some existing distance and similarity measures. The new distance measure for AIFSs is defined in Section 4, together with its properties and proofs. Numerical examples are presented in Section 5 to facilitate comparative analysis. The application of the proposed distance measure in MADM is discussed in Section 6. Some conclusions are given in Section 7. 


\section{Preliminaries}

In this section, we briefly recall some basic knowledge related to AIFSs to facilitate subsequent exposition.

Definition 1 ([1]). Let a non-empty set $X=\left\{x_{1}, x_{2}, \cdots, x_{n}\right\}$ be the universe of discourse. Then a fuzzy set $A$ in $\mathrm{X}$ is defined as follows:

$$
A=\left\{\left\langle x, \mu_{A}(x)\right\rangle \mid x \in X\right\}
$$

where $\mu_{A}(x): X \rightarrow[0,1]$ is the membership degree.

Definition 2 ([2]). An intuitionistic fuzzy set A in X defined by Atanassov can be written as:

$$
A=\left\{\left\langle x, \mu_{A}(x), v_{A}(x)\right\rangle \mid x \in X\right\}
$$

where $\mu_{A}(x): X \rightarrow[0,1]$ and $v_{A}(x): X \rightarrow[0,1]$ are the membership degree and non-membership degree, respectively, with the condition:

$$
0 \leq \mu_{A}(x)+v_{A}(x) \leq 1
$$

The hesitation degree of AIFS $A$ defined in $X$ is denoted as $\pi_{A}(x)$. It is determined by the following expression:

$$
\pi_{A}(x)=1-\mu_{A}(x)-v_{A}(x)
$$

Apparently, we can get $\pi_{A}(x) \in[0,1], \forall x \in X . \pi_{A}(x)$ is also called the intuitionistic index of $x$ to $A$. Greater $\pi_{A}(x)$ indicates more vagueness. Obviously, when $\pi_{A}(x)=0, \forall x \in X$, the AIFS degenerates into an ordinary fuzzy set.

Generally, the couple $\left\langle\mu_{A}(x), v_{A}(x)\right\rangle$ is also called an intuitionistic fuzzy value (IFV) for clarity. In the following, we use $\operatorname{AIFSs}(X)$ to denote the set of all AIFSs in $X$.

For an interval-valued fuzzy set (IVFS) $B$ in $X$, the membership degree of $x \in X$ is an interval $\left[\mu_{B L}(x), \mu_{B U}(x)\right]$. It has been pointed out by Atanassov and Gargov [29] that AIFSs and IVFSs are equivalent to each other and an AIFS $A$ can be converted into an IVFSs $B$ by the following mapping: $\mu_{B L}(x)=\mu_{A}(x)$ and $\mu_{B U}(x)=1-v_{A}(x), \forall x \in X$. Similarly, an IVFS B can be converted to an AIFS $A$ by the mapping: $\mu_{A}(x)=\mu_{B L}(x)$ and $v_{A}(x)=1-\mu_{B U}(x), \forall x \in X$. Hence, the corresponding relation between AIFSs and IVFSs provides us a possibility to consider AIFSs from the perspective of IVFSs.

Definition 3 ([2]). For two AIFSs $A \in \operatorname{AIFSs}(X)$ and $B \in \operatorname{AIFSs}(X)$, some relations between them are defined as:

(R1) $A \subseteq B \Leftrightarrow \forall x \in X \mu_{A}(x) \leq \mu_{B}(x), v_{A}(x) \geq v_{B}(x)$;

(R2) $A=B \Leftrightarrow \forall x \in X \mu_{A}(x)=\mu_{B}(x), v_{A}(x)=v_{B}(x)$;

(R3) $A^{C}=\left\{\left\langle x, v_{A}(x), \mu_{A}(x)\right\rangle \mid x \in X\right\}$, where $A^{C}$ is called as the complement of AIFS $A$.

Definition 4 ([2]). For two IFVs $a=\left\langle\mu_{a}, v_{a}\right\rangle, b=\left\langle\mu_{b}, v_{b}\right\rangle$, they can be ranked by the partial order as: $a \leq b \Leftrightarrow \mu_{a} \leq \mu_{b}, v_{a} \geq v_{b}$.

Based on this partial raked order, in the space of IFV, we can get the smallest IFV as $\langle 0,1\rangle$, denoted by 0 , and the largest IFV is $\langle 1,0\rangle$, denoted by $\mathbf{1}$.

For a linear order of IFVs, Chen and Tan [30] introduced the score function for an IFV $a=$ $\left\langle\mu_{a}, v_{a}\right\rangle$ as $S(a)=\mu_{a}-v_{a}$ to rank multiple IFVs. Following the introduction of score function, Hong and Choi [31] developed the accuracy function for IFV $a=\left\langle\mu_{a}, v_{a}\right\rangle$ as $H(a)=\mu_{a}+v_{a}$ to evaluate the accuracy degree of an IFV. Then, $\mathrm{Xu}$ and Yager [32] proposed a linear order relation between IFVs. For two IFVs $a=\left\langle\mu_{a}, v_{a}\right\rangle$ and $b=\left\langle\mu_{b}, v_{b}\right\rangle$, we have: (1) $S(a)>S(b) \Rightarrow a>b$; (2) $S(a)=S(b), H(a)=H(b) \Rightarrow a=b$; and (3) $S(a)=S(b), H(a)>H(b) \Rightarrow a>b$. 
Another two important concepts for AIFSs are the distance measure and similarity measure, which are usually used to compare the intuitionistic fuzzy information. The axiomatic definition of distance for AIFSs was introduced by Wang and Xin [13] as following.

Definition 5 ([13]). Let $D$ denote a mapping $D:$ AIFS $\times$ AIFS $\rightarrow[0,1]$, if $D(A, B)$ satisfies the following properties, $D(A, B)$ is called a distance measure between $A \in A \operatorname{IFSs}(X)$ and $B \in \operatorname{AIFSs}(X)$.

(DP1) $\quad 0 \leq D(A, B) \leq 1$;

(DP2) $D(A, B)=0$, if and only if $A=B$;

(DP3) $\quad D(A, B)=D(B, A)$;

(DP4) If $A \subseteq B \subseteq C$, then $D(A, B) \leq D(A, C)$, and $D(B, C) \leq D(A, C)$.

The definition of intuitionistic fuzzy similarity measure was proposed by Li and Cheng [14] and later discussed by Mitchell [15].

Definition 6 ([14]). A mapping $S:$ AIFS $\times$ AIFS $\rightarrow[0,1]$ is called a similarity measure between $A \in$ $\operatorname{AIFSs}(X)$ and $B \in \operatorname{AIFSs}(X)$, if $S(A, B)$ satisfies the following properties:

(SP1) $\quad(S P 1) 0 \leq S(A, B) \leq 1$;

(SP2) $S(A, B)=1$, if and only if $A=B$;

(SP3) $S(A, B)=S(B, A)$;

(SP4) If $A \subseteq B \subseteq C$, then $S(A, B) \geq S(A, C)$, and $S(B, C) \geq S(A, C)$.

Distance and similarity measures are usually regarded as a couple of complementary concepts. Thus, distance measures can be used to define similarity measures, and vice versa. For example, $D(A, B)$ $=1-S(A, B)$ can be used to measure the distance between AIFSs $A$ and $B$, if $S(A, B)$ is the similarity measure between $A$ and $B$.

\section{Reviewing on Existing Distance and Similarity Measures}

Let un-empty set $X=\left\{x_{1}, x_{2}, \cdots, x_{n}\right\}$ be the universe of discourse. Suppose that $A$ and $B$ are two intuitionistic fuzzy sets in X. Szmidt and Kacprzyk [11] proposed some distance measures between IFSs $A$ and $B$ based on the well-known Hamming distance and Euclidean distance.

The Hamming distance between AIFSs $A$ and $B$ is as:

$$
D_{H}(A, B)=\frac{1}{2} \sum_{i=1}^{n}\left(\left|\mu_{A}\left(x_{i}\right)-\mu_{B}\left(x_{i}\right)\right|+\left|v_{A}\left(x_{i}\right)-v_{B}\left(x_{i}\right)\right|+\left|\pi_{A}\left(x_{i}\right)-\pi_{B}\left(x_{i}\right)\right|\right)
$$

The normalized Hamming distance between AIFSs $A$ and $B$ is as:

$$
D_{N H}(A, B)=\frac{1}{2 n} \sum_{i=1}^{n}\left(\left|\mu_{A}\left(x_{i}\right)-\mu_{B}\left(x_{i}\right)\right|+\left|v_{A}\left(x_{i}\right)-v_{B}\left(x_{i}\right)\right|+\left|\pi_{A}\left(x_{i}\right)-\pi_{B}\left(x_{i}\right)\right|\right)
$$

The Euclidean distance between AIFSs $A$ and $B$ is as:

$$
D_{E}(A, B)=\sqrt{\frac{1}{2} \sum_{i=1}^{n}\left(\left(\mu_{A}\left(x_{i}\right)-\mu_{B}\left(x_{i}\right)\right)^{2}+\left(v_{A}\left(x_{i}\right)-v_{B}\left(x_{i}\right)\right)^{2}+\left(\pi_{A}\left(x_{i}\right)-\pi_{B}\left(x_{i}\right)\right)^{2}\right)}
$$

The normalized Euclidean distance between AIFSs $A$ and $B$ is as:

$$
D_{N E}(A, B)=\sqrt{\frac{1}{2 n} \sum_{i=1}^{n}\left(\left(\mu_{A}\left(x_{i}\right)-\mu_{B}\left(x_{i}\right)\right)^{2}+\left(v_{A}\left(x_{i}\right)-v_{B}\left(x_{i}\right)\right)^{2}+\left(\pi_{A}\left(x_{i}\right)-\pi_{B}\left(x_{i}\right)\right)^{2}\right)}
$$


$\mathrm{Xu}$ [33] generalized the abovementioned distance measures as follows:

$$
\begin{gathered}
D(A, B)=\left[\frac{1}{2} \sum_{i=1}^{n}\left(\left|\mu_{A}\left(x_{i}\right)-\mu_{B}\left(x_{i}\right)\right|^{\alpha}+\left|v_{A}\left(x_{i}\right)-v_{B}\left(x_{i}\right)\right|^{\alpha}+\left|\pi_{A}\left(x_{i}\right)-\pi_{B}\left(x_{i}\right)\right|^{\alpha}\right)\right]^{1 / \alpha} \\
D_{n}(A, B)=\left[\frac{1}{2 n} \sum_{i=1}^{n}\left(\left|\mu_{A}\left(x_{i}\right)-\mu_{B}\left(x_{i}\right)\right|^{\alpha}+\left|v_{A}\left(x_{i}\right)-v_{B}\left(x_{i}\right)\right|^{\alpha}+\left|\pi_{A}\left(x_{i}\right)-\pi_{B}\left(x_{i}\right)\right|^{\alpha}\right)\right]^{1 / \alpha}
\end{gathered}
$$

Li and Cheng [14] introduced an intuitionistic fuzzy similarity measure $S_{D C}$ as:

$$
S_{D C}(A, B)=1-\sqrt[p]{\frac{\sum_{i=1}^{n}\left|\varphi_{A}\left(x_{i}\right)-\varphi_{B}\left(x_{i}\right)\right|^{p}}{n}}
$$

where $\varphi_{A}\left(x_{i}\right)=\frac{\mu_{A}\left(x_{i}\right)+1-v_{A}\left(x_{i}\right)}{2}, \varphi_{B}\left(x_{i}\right)=\frac{\mu_{B}\left(x_{i}\right)+1-v_{B}\left(x_{i}\right)}{2}$.

Mitchell [15] proposed a general similarity measure $S_{H B}$ defined as:

$$
S_{H B}(A, B)=\frac{1}{2}\left(\rho_{\mu}(A, B)+\rho_{v}(A, B)\right)
$$

where $\rho_{\mu}(A, B)=1-\sqrt[p]{\frac{\sum_{i=1}^{n}\left|\mu_{A}\left(x_{i}\right)-\mu_{B}\left(x_{i}\right)\right|^{p}}{n}}, \rho_{v}(A, B)=1-\sqrt[p]{\frac{\sum_{i=1}^{n}\left|v_{A}\left(x_{i}\right)-v_{B}\left(x_{i}\right)\right|^{p}}{n}}$.

Hong and Kim [34] defined a similarity measure for vague sets, which are proved to be identical to AIFSs:

$$
S_{H K}(A, B)=1-\frac{\sum_{i=1}^{n}\left|\left(\mu_{A}\left(x_{i}\right)-\mu_{B}\left(x_{i}\right)\right)-\left(v_{A}\left(x_{i}\right)-v_{B}\left(x_{i}\right)\right)\right|}{2 n}
$$

Liang and Shi [16] proposed a similarity measure $S_{w}^{p}(A, B)$ for AIFSs $A$ and $B$ :

$$
S_{w}^{p}(A, B)=1-\sqrt[p]{\sum_{i=1}^{n} \sum_{m=1}^{3}\left(\omega_{m} \varphi_{m}\left(x_{i}\right)\right)^{p} / n}
$$

where

$$
\begin{gathered}
\varphi_{1}\left(x_{i}\right)=\left|\mu_{A}\left(x_{i}\right)-\mu_{B}\left(x_{i}\right)\right| / 2+\left|\left(1-v_{A}\left(x_{i}\right)\right)-\left(1-v_{B}\left(x_{i}\right)\right)\right| / 2, \\
\varphi_{2}\left(x_{i}\right)=\left|\left(\mu_{A}\left(x_{i}\right)+1-v_{A}\left(x_{i}\right)\right) / 2-\left(\mu_{B}\left(x_{i}\right)+1-v_{B}\left(x_{i}\right)\right) / 2\right|, \\
\varphi_{3}\left(x_{i}\right)=\max \left(\pi_{A}\left(x_{i}\right) / 2, \pi_{B}\left(x_{i}\right) / 2\right)-\min \left(\pi_{A}\left(x_{i}\right) / 2, \pi_{B}\left(x_{i}\right) / 2\right), 0 \leq \omega_{m} \leq 1, \text { and } \sum_{m=1}^{3} \omega_{m}=1 .
\end{gathered}
$$

The distance measure $D_{W}(A, B)$ introduced by Wang and Xin [13] is defined as:

$$
D_{W}(A, B)=\frac{1}{n} \sum_{i=1}^{n}\left(\frac{\left|\mu_{A}\left(x_{i}\right)-\mu_{B}\left(x_{i}\right)\right|+\left|v_{A}\left(x_{i}\right)-v_{B}\left(x_{i}\right)\right|}{4}+\frac{\max \left(\left|\mu_{A}\left(x_{i}\right)-\mu_{B}\left(x_{i}\right)\right|,\left|v_{A}\left(x_{i}\right)-v_{B}\left(x_{i}\right)\right|\right)}{2}\right)
$$

Hung and Yang [17] proposed several kinds of intuitionistic fuzzy similarity measures as following:

$$
\begin{gathered}
S_{H Y}^{1}(A, B)=\frac{1}{n} \sum_{i=1}^{n} \frac{\min \left(\mu_{A}\left(x_{i}\right), \mu_{B}\left(x_{i}\right)\right)+\min \left(v_{A}\left(x_{i}\right), v_{B}\left(x_{i}\right)\right)}{\max \left(\mu_{A}\left(x_{i}\right), \mu_{B}\left(x_{i}\right)\right)+\max \left(v_{A}\left(x_{i}\right), v_{B}\left(x_{i}\right)\right)} \\
S_{H Y}^{2}(A, B)=\frac{1}{n} \sum_{i=1}^{n}\left(1-\left(\left|\mu_{A}\left(x_{i}\right)-\mu_{B}\left(x_{i}\right)\right|,\left|v_{A}\left(x_{i}\right)-v_{B}\left(x_{i}\right)\right|\right) / 2\right) \\
S_{H Y}^{3}(A, B)=\frac{\sum_{i=1}^{n} \min \left(\mu_{A}\left(x_{i}\right), \mu_{B}\left(x_{i}\right)\right)+\min \left(v_{A}\left(x_{i}\right), v_{B}\left(x_{i}\right)\right)}{\sum_{i=1}^{n} \max \left(\mu_{A}\left(x_{i}\right), \mu_{B}\left(x_{i}\right)\right)+\max \left(v_{A}\left(x_{i}\right), v_{B}\left(x_{i}\right)\right)}
\end{gathered}
$$




$$
\begin{gathered}
S_{H Y}^{4}(A, B)=1-\frac{1}{2}\left(\max \left(\left|\mu_{A}\left(x_{i}\right)-\mu_{B}\left(x_{i}\right)\right|\right)+\max \left(\left|v_{A}\left(x_{i}\right)-v_{B}\left(x_{i}\right)\right|\right)\right) \\
S_{H Y}^{5}(A, B)=1-\frac{\sum_{i=1}^{n}\left(\left|\mu_{A}\left(x_{i}\right)-\mu_{B}\left(x_{i}\right)\right|+\left|v_{A}\left(x_{i}\right)-v_{B}\left(x_{i}\right)\right|\right)}{\sum_{i=1}^{n}\left(\left|\mu_{A}\left(x_{i}\right)+\mu_{B}\left(x_{i}\right)\right|+\left|v_{A}\left(x_{i}\right)+v_{B}\left(x_{i}\right)\right|\right)}
\end{gathered}
$$

By discriminate the information conveyed by different AIFSs, Vlachos and Sergiadis [12] introduced the concept of discrimination degree between AIFSs, which was expressed as $I_{I F S}(A, B)$ :

$$
I_{I F S}(A, B)=\sum_{i=1}^{n} \mu_{A}\left(x_{i}\right) \ln \frac{2 \mu_{A}\left(x_{i}\right)}{\mu_{A}\left(x_{i}\right)+\mu_{B}\left(x_{i}\right)}+v_{A}\left(x_{i}\right) \ln \frac{2 v_{A}\left(x_{i}\right)}{v_{A}\left(x_{i}\right)+v_{B}\left(x_{i}\right)}
$$

The distance measure based on discrimination is defined as:

$$
D_{V S}(A, B)=\frac{1}{2 n \ln 2}\left(I_{I F S}(A, B)+I_{I F S}(B, A)\right)
$$

$\mathrm{Xu}$ and Yager [20] presented a similarity measure for AIFSs $A$ and $B$ :

$$
S_{X Y}(A, B)=\left\{\begin{array}{l}
0.5, \text { if } A=B=B^{C} \\
D_{N H}\left(A, B^{C}\right) /\left(D_{N H}(A, B)+D_{N H}\left(A, B^{C}\right)\right), \text { otherwise }
\end{array}\right.
$$

where $B^{C}$ is the complement of $B$ and $D_{N H}(A, B)$ is the normalized Hamming distance.

$\mathrm{Xia}$ and $\mathrm{Xu}[21]$ introduced several similarity measures based on intuitionistic fuzzy operators:

$$
\begin{gathered}
S_{D_{k}}^{\eta}(A, B)=1-\left[\frac{1}{n} \sum_{i=1}^{n}\left(\left|(1-k) t_{a_{i}}-k t_{b_{i}}\right|^{\eta}\right)\right]^{1 / \eta} \\
S_{F_{k, \lambda}}^{\eta}(A, B)=1-\left[\frac{1}{2 n} \sum_{i=1}^{n}\left(\left|(1-k) t_{a_{i}}-k t_{b_{i}}\right|^{\eta}+\left|(1-\lambda) t_{b_{i}}-\lambda t_{a_{i}}\right|^{\eta}+\left|(1-k-\lambda)\left(t_{a_{i}}+t_{b_{i}}\right)\right|^{\eta}\right)\right]^{1 / \eta} \\
S_{G_{k, \lambda}}^{\eta}(A, B)=1-\left[\frac{1}{2 n} \sum_{i=1}^{n}\left(\left|k t_{a_{i}}\right|^{\eta}+\left|\lambda t_{b_{i}}\right|^{\eta}+\left|k t_{a_{i}}+\lambda t_{b_{i}}\right|^{\eta}\right)\right]^{1 / \eta}
\end{gathered}
$$

where $k, \lambda \in[0,1], k+\lambda \leq 1, t_{a_{i}}=\mu_{A}\left(x_{i}\right)-\mu_{B}\left(x_{i}\right)$ and $t_{b_{i}}=v_{A}\left(x_{i}\right)-v_{B}\left(x_{i}\right)$.

\section{A New Distance Measure between AIFSs}

In above mentioned distance and similarity measures, some of them may bring counter-intuitive results in applications. Some new developed distance/similarity measures have complicated expressions, but without specific physical meaning. In this section, we will propose a new intuitionistic fuzzy distance measure for AIFSs from the interval view. As mentioned above, an Atanassov's intuitionistic fuzzy set can be expressed in the form of interval fuzzy set. So we can define a distance measure for AIFSs from the perspective of interval comparison.

For an AIFS $A=\left\{\left\langle x, \mu_{A}(x), v_{A}(x)\right\rangle \mid x \in X\right\}$ defined in $X=\left\{x_{1}, x_{2}, \cdots, x_{n}\right\}$, it indicates that the membership degree of $x_{i}$ to $A$ is unknown, with lower bound and upper bound as $\mu_{A}\left(x_{i}\right)$ and $1-$ $v_{A}\left(x_{i}\right)$, respectively. In other words, the membership degree of $x_{i}$ to $A$ is an interval $\left[\mu_{A}\left(x_{i}\right), 1-v_{A}\left(x_{i}\right)\right]$, $i=1,2, \cdots, n$. So the distance between two AIFSs $A$ and $B$ in the same universe $X=\left\{x_{1}, x_{2}, \cdots, x_{n}\right\}$ can be measured by comparing interval sequences $\left[\mu_{A}\left(x_{i}\right), 1-v_{A}\left(x_{i}\right)\right]$ and $\left[\mu_{B}\left(x_{i}\right), 1-v_{B}\left(x_{i}\right)\right], i=$ $1,2, \cdots, n$.

Distances between interval values have been reviewed in Reference [35]. It was pointed that the distance proposed in Reference [36] violates the property of reflexivity. Thus Irpino and Verde [35] developed a Wasserstein distance from the view of one-dimensional uniform distribution, rather than 
from the view of two-dimensional uniform distribution in Reference [36]. The Wasserstein distance measure for interval values is given as following.

Definition 7 ([35]). Given two interval values $a=\left[a_{1}, a_{2}\right]$ and $b=\left[b_{1}, b_{2}\right]$, the distance between them id defined as:

$$
d^{I}(a, b)=d^{I}(a, b)=\sqrt{\int_{0}^{1}\left[\left(\frac{a_{1}+a_{2}}{2}-\frac{b_{1}+b_{2}}{2}\right)+\left(\frac{a_{2}-a_{1}}{2}-\frac{b_{2}-b_{1}}{2}\right)(2 t-1)\right]^{2} d t}=\sqrt{\left(\frac{a_{1}+a_{2}}{2}-\frac{b_{1}+b_{2}}{2}\right)^{2}+\frac{1}{3}\left(\frac{a_{2}-a_{1}}{2}-\frac{b_{2}-b_{1}}{2}\right)^{2}}
$$

So $\forall i \in\{1,2, \cdots, n\}$, for $A_{x_{i}}=\left\langle\mu_{A}\left(x_{i}\right), v_{A}\left(x_{i}\right)\right\rangle$ and $B_{x_{i}}=\left\langle\mu_{B}\left(x_{i}\right), v_{B}\left(x_{i}\right)\right\rangle$, the distance between their corresponding interval values $\left[\mu_{A}\left(x_{i}\right), 1-v_{A}\left(x_{i}\right)\right]$ and $\left[\mu_{B}\left(x_{i}\right), 1-v_{B}\left(x_{i}\right)\right]$ can be expressed by:

$$
d^{I}\left(A_{x_{i}}, B_{x_{i}}\right)=\sqrt{\left(\frac{\mu_{A}\left(x_{i}\right)+1-v_{A}\left(x_{i}\right)}{2}-\frac{\mu_{B}\left(x_{i}\right)+1-v_{B}\left(x_{i}\right)}{2}\right)^{2}+\frac{1}{3}\left(\frac{1-v_{A}\left(x_{i}\right)-\mu_{A}\left(x_{i}\right)}{2}-\frac{1-v_{B}\left(x_{i}\right)-\mu_{B}\left(x_{i}\right)}{2}\right)^{2}}
$$

which can be further written as:

$$
d^{I}\left(A_{x_{i}}, B_{x_{i}}\right)=\sqrt{\left(\frac{\mu_{A}\left(x_{i}\right)-v_{A}\left(x_{i}\right)}{2}-\frac{\mu_{B}\left(x_{i}\right)-v_{B}\left(x_{i}\right)}{2}\right)^{2}+\frac{1}{3}\left(\frac{\mu_{A}\left(x_{i}\right)+v_{A}\left(x_{i}\right)}{2}-\frac{\mu_{B}\left(x_{i}\right)+v_{B}\left(x_{i}\right)}{2}\right)^{2}}
$$

or

$$
d^{I}\left(A_{x_{i}}, B_{x_{i}}\right)=\sqrt{\left(\frac{\mu_{A}\left(x_{i}\right)-v_{A}\left(x_{i}\right)}{2}-\frac{\mu_{B}\left(x_{i}\right)-v_{B}\left(x_{i}\right)}{2}\right)^{2}+\frac{1}{3}\left(\frac{\pi_{A}\left(x_{i}\right)}{2}-\frac{\pi_{B}\left(x_{i}\right)}{2}\right)^{2}}
$$

Since all parameters $\mu_{A}\left(x_{i}\right), v_{A}\left(x_{i}\right), \pi_{A}\left(x_{i}\right), \mu_{B}\left(x_{i}\right), v_{B}\left(x_{i}\right), \pi_{B}\left(x_{i}\right)$ take values in the interval $[0,1]$, we have $-1 \leq \mu_{A}\left(x_{i}\right)-v_{A}\left(x_{i}\right) \leq 1,-1 \leq \mu_{B}\left(x_{i}\right)-v_{B}\left(x_{i}\right) \leq 1$. Then the maximum value of $d^{I}\left(A_{x_{i}}, B_{x_{i}}\right)$ can be got as 1 , which is obtained when $A_{x_{i}}=\langle 0,1\rangle, B_{x_{i}}=\langle 1,0\rangle$ and $A_{x_{i}}=\langle 1,0\rangle$, $B_{x_{i}}=\langle 0,1\rangle$ (this will be proved in follow-up exposition). Thus, the relation $0 \leq d^{I}\left(A_{x_{i}}, B_{x_{i}}\right) \leq 1$ can be obtained.

Based on above analysis, we can propose a new definition of distance measure for Atanassov's intuitionistic fuzzy sets. Suppose that $A$ and $B$ are two AIFSs defined in $X=\left\{x_{1}, x_{2}, \cdots, x_{n}\right\}$, expressed as $A=\left\{\left\langle x, \mu_{A}(x), v_{A}(x)\right\rangle \mid x \in X\right\}$ and $B=\left\{\left\langle x, \mu_{B}(x), v_{B}(x)\right\rangle \mid x \in X\right\}$, respectively, the distance between them can be calculated by the following expression:

$$
D^{I}(A, B)=\frac{1}{n} \sum_{i=1}^{n} \sqrt{\left(\frac{\mu_{A}\left(x_{i}\right)-v_{A}\left(x_{i}\right)}{2}-\frac{\mu_{B}\left(x_{i}\right)-v_{B}\left(x_{i}\right)}{2}\right)^{2}+\frac{1}{3}\left(\frac{\mu_{A}\left(x_{i}\right)+v_{A}\left(x_{i}\right)}{2}-\frac{\mu_{B}\left(x_{i}\right)+v_{B}\left(x_{i}\right)}{2}\right)^{2}}
$$

Theorem 1. For two AIFSs $A$ and $B$ defined in $X=\left\{x_{1}, x_{2}, \cdots, x_{n}\right\}, D^{I}(A, B)=0$ if and only if $A=B$.

\section{Proof.}

(i) Given $D^{I}(A, B)=0$, we can get $\frac{\mu_{A}\left(x_{i}\right)-v_{A}\left(x_{i}\right)}{2}-\frac{\mu_{B}\left(x_{i}\right)-v_{B}\left(x_{i}\right)}{2}=0$ and $\frac{\mu_{A}\left(x_{i}\right)+v_{A}\left(x_{i}\right)}{2}-$ $\frac{\mu_{B}\left(x_{i}\right)+v_{B}\left(x_{i}\right)}{2}=0 \forall i \in\{1,2, \cdots, n\}$, which can be written identically as:

$$
\begin{aligned}
& \mu_{A}\left(x_{i}\right)-v_{A}\left(x_{i}\right)=\mu_{B}\left(x_{i}\right)-v_{B}\left(x_{i}\right) \\
& \mu_{A}\left(x_{i}\right)+v_{A}\left(x_{i}\right)=\mu_{B}\left(x_{i}\right)+v_{B}\left(x_{i}\right)
\end{aligned}
$$

Then we can get $\mu_{A}\left(x_{i}\right)=\mu_{B}\left(x_{i}\right)$ and $v_{A}\left(x_{i}\right)=v_{B}\left(x_{i}\right)$ by adding and subtracting Equations (32) and (33) respectively, $i=1,2, \cdots, n$. Hence, for all elements $x \in X, \mu_{A}(x)=\mu_{B}(x)$ and $v_{A}(x)=v_{B}(x)$ hold simultaneously, which indicates that $A=B$.

(ii) For two AIFS $A$ and $B$ defined in $X=\left\{x_{1}, x_{2}, \cdots, x_{n}\right\}$, we have the following relation:

$$
A=B \Rightarrow \forall i \in\{1,2, \cdots, n\}, \mu_{A}\left(x_{i}\right)=\mu_{B}\left(x_{i}\right), v_{A}\left(x_{i}\right)=v_{B}\left(x_{i}\right) \Rightarrow D^{I}(A, B)=0 .
$$


From above analysis, we can conclude that $D^{I}(A, B)=0 \Leftrightarrow A=B$.

Theorem 2. For two AIFSs $A$ and $B$ defined in $X=\left\{x_{1}, x_{2}, \cdots, x_{n}\right\}, D^{I}(A, B)=D^{I}(B, A)$.

Proof. From Equation (31), we can get $D^{I}(B, A)$ as:

$$
\begin{aligned}
D^{I}(B, A) & =\frac{1}{n} \sum_{i=1}^{n} \sqrt{\left(\frac{\mu_{B}\left(x_{i}\right)-v_{B}\left(x_{i}\right)}{2}-\frac{\mu_{A}\left(x_{i}\right)-v_{A}\left(x_{i}\right)}{2}\right)^{2}+\frac{1}{3}\left(\frac{\mu_{B}\left(x_{i}\right)+v_{B}\left(x_{i}\right)}{2}-\frac{\mu_{A}\left(x_{i}\right)+v_{A}\left(x_{i}\right)}{2}\right)^{2}} \\
& =\frac{1}{n} \sum_{i=1}^{n} \sqrt{\left(\frac{\mu_{A}\left(x_{i}\right)-v_{A}\left(x_{i}\right)}{2}-\frac{\mu_{B}\left(x_{i}\right)-v_{B}\left(x_{i}\right)}{2}\right)^{2}+\frac{1}{3}\left(\frac{\mu_{A}\left(x_{i}\right)+v_{A}\left(x_{i}\right)}{2}-\frac{\mu_{B}\left(x_{i}\right)+v_{B}\left(x_{i}\right)}{2}\right)^{2}} \\
& =D^{I}(A, B) .
\end{aligned}
$$

Therefore, we have $D^{I}(A, B)=D^{I}(B, A)$.

Theorem 3. For three AIFSs $A, B$ and $C$ defined in $X=\left\{x_{1}, x_{2}, \cdots, x_{n}\right\}$, if $A \subseteq B \subseteq C$, then $D^{I}(A, B) \leq$ $D^{I}(A, C), D^{I}(B, C) \leq D^{I}(A, C)$.

Proof. Three AIFSs $A, B$, and $C$ defined in $X=\left\{x_{1}, x_{2}, \cdots, x_{n}\right\}$ can be expressed as $A=\left\{\left\langle x, \mu_{A}(x), v_{A}(x)\right\rangle \mid x \in X\right\}, B=\left\{\left\langle x, \mu_{B}(x), v_{B}(x)\right\rangle \mid x \in X\right\}, C=\left\{\left\langle x, \mu_{C}(x), v_{C}(x)\right\rangle \mid x \in X\right\}$, respectively. Considering the condition $A \subseteq B \subseteq C$, we have the relations $\mu_{A}\left(x_{i}\right) \leq \mu_{B}\left(x_{i}\right) \leq \mu_{C}\left(x_{i}\right)$ and $v_{A}\left(x_{i}\right) \geq v_{B}\left(x_{i}\right) \geq v_{C}\left(x_{i}\right)$.

The distance between AIFSs $A$ and $B$ can be written as:

$$
D^{I}(A, B)=\frac{1}{n} \sum_{i=1}^{n} \sqrt{\left(\frac{\mu_{A}\left(x_{i}\right)-v_{A}\left(x_{i}\right)}{2}-\frac{\mu_{B}\left(x_{i}\right)-v_{B}\left(x_{i}\right)}{2}\right)^{2}+\frac{1}{3}\left(\frac{\mu_{A}\left(x_{i}\right)+v_{A}\left(x_{i}\right)}{2}-\frac{\mu_{B}\left(x_{i}\right)+v_{B}\left(x_{i}\right)}{2}\right)^{2}}
$$

The distance between AIFSs $A$ and $C$ can be written as:

$$
D^{I}(A, C)=\frac{1}{n} \sum_{i=1}^{n} \sqrt{\left(\frac{\mu_{A}\left(x_{i}\right)-v_{A}\left(x_{i}\right)}{2}-\frac{\mu_{C}\left(x_{i}\right)-v_{C}\left(x_{i}\right)}{2}\right)^{2}+\frac{1}{3}\left(\frac{\mu_{A}\left(x_{i}\right)+v_{A}\left(x_{i}\right)}{2}-\frac{\mu_{C}\left(x_{i}\right)+v_{C}\left(x_{i}\right)}{2}\right)^{2}}
$$

The distance between AIFSs $B$ and $C$ can be written as:

$$
D^{I}(B, C)=\frac{1}{n} \sum_{i=1}^{n} \sqrt{\left(\frac{\mu_{B}\left(x_{i}\right)-v_{B}\left(x_{i}\right)}{2}-\frac{\mu_{C}\left(x_{i}\right)-v_{C}\left(x_{i}\right)}{2}\right)^{2}+\frac{1}{3}\left(\frac{\mu_{B}\left(x_{i}\right)+v_{B}\left(x_{i}\right)}{2}-\frac{\mu_{C}\left(x_{i}\right)+v_{C}\left(x_{i}\right)}{2}\right)^{2}}
$$

Then we construct a function $f(x, y)$ with two variables as:

$$
f(x, y)=((x-y)-(a-b))^{2}+\frac{1}{3}((x+y)-(a+b))^{2}
$$

where $0 \leq x \leq 1,0 \leq y \leq 1,0 \leq a \leq 1,0 \leq b \leq 1$.

The partial derivatives for variables $x$ and $y$ can be obtained:

$$
\begin{gathered}
\frac{\partial f}{\partial x}=2((x-y)-(a-b))+\frac{2}{3}((x+y)-(a+b))=\frac{8}{3}(x-a)+\frac{4}{3}(b-y)=\frac{4}{3}(2(x-a)+(b-y)) \\
\frac{\partial f}{\partial y}=-2((x-y)-(a-b))+\frac{2}{3}((x+y)-(a+b))=\frac{8}{3}(y-b)+\frac{4}{3}(a-x)=\frac{4}{3}(2(y-b)+(a-x))
\end{gathered}
$$

(i) Given the condition $0 \leq a \leq x \leq 1$ and $0 \leq y \leq b \leq 1$, we can obtain that $\partial f / \partial x \geq 0$ and $\partial f / \partial y \leq 0$. Thus, $f(x, y)$ is an increasing function of variable $x$, and it is a decreasing function of variable $y$. Let $a=\mu_{A}\left(x_{i}\right), b=v_{A}\left(x_{i}\right)$ then $a=\mu_{A}\left(x_{i}\right) \leq \mu_{B}\left(x_{i}\right) \leq \mu_{C}\left(x_{i}\right)$ and $b=v_{A}\left(x_{i}\right) \geq v_{B}\left(x_{i}\right) \geq v_{C}\left(x_{i}\right), i \in\{1,2, \cdots, n\}$. Considering the monotonicity of $f(x, y)$, 
we have $f\left(\mu_{B}\left(x_{i}\right), v_{B}\left(x_{i}\right)\right) \leq f\left(\mu_{C}\left(x_{i}\right), v_{C}\left(x_{i}\right)\right), \forall i \in\{1,2, \cdots, n\}$. Under the condition $a=$ $\mu_{A}\left(x_{i}\right), b=v_{A}\left(x_{i}\right), \forall i \in\{1,2, \cdots, n\}$, the following expressions hold:

$$
D^{I}(A, C)=\frac{1}{2 n} \sum_{i=1}^{n} \sqrt{f\left(\mu_{C}\left(x_{i}\right), v_{C}\left(x_{i}\right)\right)}, D^{I}(A, B)=\frac{1}{2 n} \sum_{i=1}^{n} \sqrt{f\left(\mu_{B}\left(x_{i}\right), v_{B}\left(x_{i}\right)\right)} .
$$

So we have $D^{I}(A, B) \leq D^{I}(A, C)$.

(ii) In the condition $0 \leq x \leq a \leq 1$ and $0 \leq b \leq y \leq 1$, we have $\partial f / \partial x \leq 0$ and $\partial f / \partial y \geq 0$. So $f(x, y)$ is an decreasing function of variable $x$, and it is an increasing function of variable $y$. Set $a=\mu_{C}\left(x_{i}\right), b=v_{C}\left(x_{i}\right)$, then $\mu_{A}\left(x_{i}\right) \leq \mu_{B}\left(x_{i}\right) \leq \mu_{C}\left(x_{i}\right)=a$ and $v_{A}\left(x_{i}\right) \geq v_{B}\left(x_{i}\right) \geq v_{C}\left(x_{i}\right)=b, i \in\{1,2, \cdots, n\}$. Considering the monotonicity of $f(x, y)$, we have $f\left(\mu_{B}\left(x_{i}\right), v_{B}\left(x_{i}\right)\right) \leq f\left(\mu_{A}\left(x_{i}\right), v_{A}\left(x_{i}\right)\right), \forall i \in\{1,2, \cdots, n\}$. For $a=\mu_{C}\left(x_{i}\right), b=v_{C}\left(x_{i}\right)$, $\forall i \in\{1,2, \cdots, n\}$, the following expressions hold:

$$
D^{I}(A, C)=\frac{1}{2 n} \sum_{i=1}^{n} \sqrt{f\left(\mu_{A}\left(x_{i}\right), v_{A}\left(x_{i}\right)\right)}, D^{I}(B, C)=\frac{1}{2 n} \sum_{i=1}^{n} \sqrt{f\left(\mu_{B}\left(x_{i}\right), v_{B}\left(x_{i}\right)\right)} .
$$

So we have $D^{I}(B, C) \leq D^{I}(A, C)$.

Taking (i) and (ii) into account, we can conclude that $D^{I}(A, B) \leq D^{I}(A, C)$ and $D^{I}(B, C) \leq$ $D^{I}(A, C)$ in the condition of $A \subseteq B \subseteq C$.

Theorem 4. For two AIFSs $A$ and $B$ defined in $X=\left\{x_{1}, x_{2}, \cdots, x_{n}\right\}, 0 \leq D^{I}(A, B) \leq 1$.

Proof. The expression of $D^{I}(A, B)$ indicates that $D^{I}(A, B) \geq 0$. Additionally, Theorem 1 says that $D^{I}(A, B)=0$ when $A=B$.

Define two AIFSs in $X=\left\{x_{1}, x_{2}, \cdots, x_{n}\right\}$ as $F_{*}=\{\langle x, 0,1\rangle \mid x \in X\}$ and $F^{*}=\{\langle x, 1,0\rangle \mid x \in X\}$. For two AIFSs $A=\left\{\left\langle x, \mu_{A}(x), v_{A}(x)\right\rangle \mid x \in X\right\}$ and $B=\left\{\left\langle x, \mu_{B}(x), v_{B}(x)\right\rangle \mid x \in X\right\}$, we have $F_{*} \subseteq A \subseteq$ $B \subseteq F^{*}$ based on the basic relation between AIFSs shown in Definition 3.

By Theorem 3, the condition $F_{*} \subseteq A \subseteq B \subseteq F^{*}$ implies that $D^{I}(A, B) \leq D^{I}\left(F_{*}, F^{*}\right)$. Since AIFSs $A$ and $B$ are arbitrary, the relation $D^{I}(A, B) \leq D^{I}\left(F_{*}, F^{*}\right)$ holds in the set of all AIFSs defined in $X$.

By Equation (31), the distance between $F_{*}$ and $F^{*}$ can be calculated as $D^{I}\left(F_{*}, F^{*}\right)=1$. Hence $D^{I}(A, B) \leq 1$.

From above analysis, we can get $0 \leq D^{I}(A, B) \leq 1$.

Theorems 1-4 indicate that the distance $D^{I}(A, B)$ satisfies all axiomatic conditions of a distance measure. Therefore, $D^{I}(A, B)$ is a strict distance measure for AIFSs. Thus, we have the following theorem.

Theorem 5. For two AIFSs $A$ and $B$ defined in $X=\left\{x_{1}, x_{2}, \cdots, x_{n}\right\}, D^{I}(A, B)$ is the distance measure between two $A$ and $B$.

Proof. It is evident from Theorems 1-4.

Based on the definition of intuitionistic fuzzy values, we can get the distance between two IFVs. For two IFVs $\alpha=\left\langle\mu_{\alpha}, v_{\alpha}\right\rangle$ and $\beta=\left\langle\mu_{\beta}, v_{\beta}\right\rangle$, the distance between them can be measured as:

$$
D^{I}(\alpha, \beta)=\sqrt{\left(\frac{\mu_{\alpha}-v_{\alpha}}{2}-\frac{\mu_{\beta}-v_{\beta}}{2}\right)^{2}+\frac{1}{3}\left(\frac{\mu_{\alpha}+v_{\alpha}}{2}-\frac{\mu_{\beta}+v_{\beta}}{2}\right)^{2}}
$$


Considering the weights of $x_{i}, i=1,2, \cdots, n$, the weighted distance between two AIFSs $A$ and $B$ in $X=\left\{x_{1}, x_{2}, \cdots, x_{n}\right\}$ can be measured as:

$$
D_{W}^{I}(A, B)=\sum_{i=1}^{n} w_{i} \sqrt{\left(\frac{\mu_{A}\left(x_{i}\right)-v_{A}\left(x_{i}\right)}{2}-\frac{\mu_{B}\left(x_{i}\right)-v_{B}\left(x_{i}\right)}{2}\right)^{2}+\frac{1}{3}\left(\frac{\mu_{A}\left(x_{i}\right)+v_{A}\left(x_{i}\right)}{2}-\frac{\mu_{B}\left(x_{i}\right)+v_{B}\left(x_{i}\right)}{2}\right)^{2}}
$$

where $w_{i}$ is the weighting factor of $x_{i}, i=1,2, \cdots, n, w_{i} \in[0,1]$ and $\sum_{i=1}^{n} w_{i}=1$.

Theorem 6. $D_{W}^{I}(A, B)$ is a distance measure between two AIFSs $A$ and $B$ defined in $X=\left\{x_{1}, x_{2}, \cdots, x_{n}\right\}$.

Proof. It is trivial from Theorems 1-4.

\section{Numerical Examples}

In order to demonstrate the performance of the proposed distance measure in discriminating intuitionistic fuzzy information, we will present several examples in this section. For convenience, the weights of all elements in $\mathrm{X}$ are assumed as equal.

Example 1. Assumed that there are two patterns denoted by AIFSs in $X=\left\{x_{1}, x_{2}, x_{3}\right\}$. Two AIFSs representing two patterns are expressed as:

$A_{1}=\left\{\left\langle x_{1}, 0.1,0.1\right\rangle,\left\langle x_{2}, 0.1,0.3\right\rangle,<x_{3}, 0.1,0.9>\right\}$ and $A_{2}=\left\{\left\langle x_{1}, 0.7,0.2>,<x_{2}, 0.1,0.8>,<x_{3}, 0.4,0.4>\right\}\right.$.

A sample needs to be classified is denoted by AIFS $B=\left\{<x_{1}, 0.4,0.4>,<x_{2}, 0.6,0.2>,<x_{3}, 0,0.8>\right\}$.

According to the recognition principle of maximum degree of similarity and minimum distance between AIFSs, the sample $B$ belongs to the pattern $A_{k}$ satisfying: $S\left(A_{k}, B\right)=\max _{j=1,2, \cdots, m}\left\{S\left(A_{j}, B\right)\right\}$ or $D\left(A_{k}, B\right)=\min _{j=1,2, \cdots, m}\left\{D\left(A_{j}, B\right)\right\}$, where $m$ is the number of given patterns.

Based on the normalized Hamming distance measure and Euclidean distance measure for AIFSs, we can get:

$$
\begin{gathered}
D_{N H}\left(A_{1}, B\right)=D_{N H}\left(A_{2}, B\right)=0.433 ; \\
D_{N E}\left(A_{1}, B\right)=0.412, D_{N E}\left(A_{2}, B\right)=0.424 .
\end{gathered}
$$

Using the proposed distance measure $D^{I}$, we have:

$$
D^{I}\left(A_{1}, B\right)=0.1841, D^{I}\left(A_{2}, B\right)=0.4008 \text {. }
$$

We can see that the normalized Hamming distance cannot classify the sample reasonably. The normalized Euclidean distance and the proposed distance can classify the sample to $A_{1}$ based on the principle of minimum distance degree. It is also shown that the proposed measure $D^{I}$ have greater discrimination capability since the distance $D^{I}\left(A_{1}, B\right)$ is much less than $D_{N E}\left(A_{2}, B\right)$. Nevertheless, two close values $D_{N E}\left(A_{1}, B\right)$ and $D_{N E}\left(A_{2}, B\right)$ generated by normalized Euclidean distance are not helpful for making a sound decision.

Example 2. Three patterns are expressed as AIFSs in $X=\left\{x_{1}, x_{2}, x_{3}\right\}$. Three corresponding AIFSs are given as:

$$
\begin{aligned}
& A_{1}=\left\{\left\langlex_{1}, 0.4,0.5>,\left\langle x_{2}, 0.7,0.1>,\left\langle x_{3}, 0.3,0.3>\right\},\right.\right.\right. \\
& A_{2}=\left\{\left\langle x_{1}, 0.5,0.4>,<x_{2}, 0.7,0.2>,<x_{3}, 0.4,0.3>\right\},\right. \\
& A_{3}=\left\{\left\langle x_{1}, 0.4,0.5>,<x_{2}, 0.7,0.1>,<x_{3}, 0.4,0.3>\right\} .\right.
\end{aligned}
$$

A sample to be classified is given as AIFSs $B=\left\{\left\langle x_{1}, 0.1,0.1\right\rangle,\left\langle x_{2}, 1,0\right\rangle,\left\langle x_{3}, 0,1\right\rangle\right\}$. 
Based on the normalized Hamming distance and Euclidean distance measures, we can get:

$$
\begin{gathered}
D_{N H}\left(A_{1}, B\right)=D_{N H}\left(A_{2}, B\right)=D_{N H}\left(A_{3}, B\right)=0.483 ; \\
D_{N E}\left(A_{1}, B\right)=D_{N E}\left(A_{2}, B\right)=D_{N E}\left(A_{3}, B\right)=0.442 .
\end{gathered}
$$

Our proposed distance measure $D^{I}$ can lead to the following results:

$$
D^{I}\left(A_{1}, B\right)=0.3098, D^{I}\left(A_{2}, B\right)=0.3389, D^{I}\left(A_{3}, B\right)=0.3244 .
$$

We can see that the sample $B$ cannot be classified to a specific pattern based on normalized Hamming distance and Euclidean distance measures. The proposed distance measure can distinguish three pattern by assigning different values to the distance between the sample and different patterns. Based the principle of minimum distance, we can classify the sample as $A_{1}$.

Example 3. Suppose that three patterns are expressed by AIFSs defined in $X=\left\{x_{1}, x_{2}, x_{3}\right\}$, which are listed as:

$$
\begin{aligned}
& A_{1}=\left\{\left\langlex_{1}, 0.3,0.2>,\left\langle x_{2}, 0.4,0.4>,<x_{3}, 0.2,0.2>\right\},\right.\right. \\
& A_{2}=\left\{\left\langlex_{1}, 0.1,0.4>,\left\langle x_{2}, 0,0.4>,<x_{3}, 0.3,0.3>\right\},\right.\right. \\
& A_{3}=\left\{\left\langle x_{1}, 0.2,0.5\right\rangle,\left\langle x_{2}, 0.3,0.3>,<x_{3}, 0.5,0.1>\right\} .\right.
\end{aligned}
$$

A sample to be classified is given as AIFSs $B=\left\{\left\langle x_{1}, 0.4,0.5\right\rangle,\left\langle x_{2}, 0.3,0.5\right\rangle,\left\langle x_{3}, 0.4,0.2\right\rangle\right\}$.

Based on the similarity proposed by Li and Cheng, we can obtain:

$$
S_{D C}\left(A_{1}, B\right)=S_{D C}\left(A_{2}, B\right)=S_{D C}\left(A_{3}, B\right)=1-0.1 / 3^{1 / p} ;
$$

Our proposed distance measure $D^{I}$ can generate the following results:

$$
D^{I}\left(A_{1}, B\right)=0.1227, D^{I}\left(A_{2}, B\right)=0.1352, D^{I}\left(A_{3}, B\right)=0.1103 .
$$

We can see that the sample $B$ cannot be classified to a specific pattern based on the similarity introduced by $\mathrm{Li}$ and Cheng, regardless of the choice of parameter $p$. The proposed distance measure $D^{I}$ can distinguish three pattern by assigning different values to the distance between the sample and different patterns. Based the principle of minimum distance, we can classify the sample as $A_{3}$.

Example 4. Suppose that three patterns are expressed by AIFSs defined in $X=\left\{x_{1}, x_{2}, x_{3}\right\}$, which are listed as:

$$
\begin{aligned}
& A_{1}=\left\{\left\langlex_{1}, 0.1,0.5>,\left\langle x_{2}, 0.2,0.4>,<x_{3}, 0.5,0.3>\right\},\right.\right. \\
& A_{2}=\left\{<x_{1}, 0.2,0.4>,<x_{2}, 0.1,0.6>,<x_{3}, 0.8,0.1>\right\}, \\
& A_{3}=\left\{<x_{1}, 0.1,0.4>,<x_{2}, 0.1,0.1>,<x_{3}, 0.5,0.2>\right\} .
\end{aligned}
$$

A sample to be classified is given as AIFSs $\left.B=\left\{\left\langle x_{1}, 0.2,0.3\right\rangle,\left\langle x_{2}, 0.1,0.4\right\rangle,<x_{3}, 0.6,0.2\right\rangle\right\}$.

Based on the similarity proposed by Mitchell, we can obtain:

$$
\begin{gathered}
S_{H B}\left(A_{1}, B\right)=S_{H B}\left(A_{2}, B\right)=S_{H B}\left(A_{3}, B\right)=1-0.3 / 3^{1 / p} ; \\
S_{H K}\left(A_{1}, B\right)=S_{H K}\left(A_{2}, B\right)=S_{H K}\left(A_{3}, B\right)=1-0.6 / 6=0.9
\end{gathered}
$$

Our proposed distance measure $D^{I}$ can generate the following results: 


$$
D^{I}\left(A_{1}, B\right)=0.1035, D^{I}\left(A_{2}, B\right)=0.1081, D^{I}\left(A_{3}, B\right)=0.1103
$$

We can see that the value of parameter $p$ cannot affect the result that $S_{H B}\left(A_{1}, B\right)=S_{H B}\left(A_{2}, B\right)=$ $S_{H B}\left(A_{3}, B\right)$. The similarity proposed by Hong and Kim also gets an identical similarity degree between the sample and all patterns. So the similarity measures $S_{H B}$ and $S_{H K}$ cannot be used to classify sample $B$ in such example. The proposed distance measure $D^{I}$ can assign different values to the distance between the sample and different patterns. So the proposed distance measure $D^{I}$ can be used to classify the sample as $A_{1}$ based the principle of minimum distance.

Example 5. Three patterns are expressed as AIFSs in $X=\left\{x_{1}, x_{2}, x_{3}, x_{4}\right\}$. They are given as:

$$
\begin{aligned}
& A_{1}=\left\{<x_{1}, 0.3,0.4>,<x_{2}, 0.3,0.4>,<x_{3}, 0.6,0.1>,<x_{4}, 0.6,0.1>\right\}, \\
& A_{2}=\left\{\left\langle x_{1}, 0.4,0.4>,<x_{2}, 0.3,0.5\right\rangle,<x_{3}, 0.7,0.1>,<x_{4}, 0.6,0.2>\right\} \text {, } \\
& A_{3}=\left\{\left\langle x_{1}, 0.4,0.4>,<x_{2}, 0.3,0.4>,<x_{3}, 0.7,0.1>,<x_{4}, 0.6,0.1>\right\}\right. \text {. }
\end{aligned}
$$

A sample to be classified is given as AIFSs $B=\left\{\left\langle x_{1}, 0.35,0.65\right\rangle,\left\langle x_{2}, 0.55,0.45\right\rangle\right.$, $\left.<x_{3}, 0.65,0.1>,<x_{4}, 0.6,0.15>\right\}$.

According to the similarity measure proposed by Liang and Shi [16], when $p=1$ and $\omega_{1}=\omega_{2}=$ $\omega_{3}=1 / 3$, we can get the results as following:

$$
\begin{gathered}
S_{w}^{1}\left(A_{1}, B\right)=S_{w}^{1}\left(A_{2}, B\right)=S_{w}^{1}\left(A_{3}, B\right)=1-19 / 240=0.921 \\
D_{W}\left(A_{1}, B\right)=D_{W}\left(A_{2}, B\right)=D_{W}\left(A_{3}, B\right)=19 / 160=0.119 .
\end{gathered}
$$

Appling the proposed distance measure $D^{\mathrm{I}}$, we can get:

$$
D^{I}\left(A_{1}, B\right)=0.0806, D^{I}\left(A_{2}, B\right)=0.0948, D^{I}\left(A_{3}, B\right)=0.0877 .
$$

In this example, we can see that neither the similarity measure proposed in Reference [16] nor the distance measure developed in Reference [13] is competent to classify the sample. In spite of their complex forms and additional parameters, they cannot distinguish these three patterns. However, the proposed distance measure $D^{I}$ can generate different values to measure the distance between the sample and there patterns. So the sample $B$ is classified as $A_{1}$ based on the minimum distance value.

Example 6. Assume that three patterns are expressed as AIFSs in $X=\left\{x_{1}, x_{2}, x_{3}\right\}$. They are given as:

$$
\begin{aligned}
& A_{1}=\left\{\left\langle x_{1}, 0.2,0.3\right\rangle,\left\langle x_{2}, 0.1,0.4>,<x_{3}, 0.2,0.6>\right\},\right. \\
& A_{2}=\left\{<x_{1}, 0.3,0.2>,<x_{2}, 0.4,0.1>,<x_{3}, 0.5,0.3>\right\}, \\
& A_{3}=\left\{<x_{1}, 0.2,0.3>,<x_{2}, 0.4,0.1>,<x_{3}, 0.5,0.3>\right\} .
\end{aligned}
$$

A sample to be classified is given as AIFSs $B=\left\{\left\langle x_{1}, 0.1,0.2\right\rangle,\left\langle x_{2}, 0.4,0.5\right\rangle,\left\langle x_{3}, 0,0\right\rangle\right\}$.

Based on the similarity proposed by Hung and Yang, we can get the following results:

$$
\begin{gathered}
S_{H Y}^{1}\left(A_{1}, B\right)=S_{H Y}^{1}\left(A_{2}, B\right)=S_{H Y}^{1}\left(A_{3}, B\right)=52 / 135=0.385, \\
S_{H Y}^{2}\left(A_{1}, B\right)=S_{H Y}^{2}\left(A_{2}, B\right)=S_{H Y}^{2}\left(A_{3}, B\right)=23 / 30=0.767, \\
S_{H Y}^{3}\left(A_{1}, B\right)=S_{H Y}^{3}\left(A_{2}, B\right)=S_{H Y}^{3}\left(A_{3}, B\right)=4 / 11=0.364, \\
S_{H Y}^{4}\left(A_{1}, B\right)=S_{H Y}^{4}\left(A_{2}, B\right)=S_{H Y}^{4}\left(A_{3}, B\right)=0.55,
\end{gathered}
$$




$$
S_{H Y}^{5}\left(A_{1}, B\right)=S_{H Y}^{5}\left(A_{2}, B\right)=S_{H Y}^{5}\left(A_{3}, B\right)=8 / 15=0.533 .
$$

According to the proposed distance measure $D^{I}$, the distance degrees between $B$ and three patterns can be yielded as following:

$$
D^{I}\left(A_{1}, B\right)=0.1720, D^{I}\left(A_{2}, B\right)=0.1994, D^{I}\left(A_{3}, B\right)=0.1801 .
$$

These results indicate that Hung and Yang's similarity measures [17] cannot discriminate three patterns. So the sample $B$ cannot be classified to any specific pattern by these similarity measures proposed in Reference [17]. It is shown that the proposed distance measure $D^{I}$ can classify the sample $B$ as $A_{1}$ based on the minimum distance principle.

Example 7. Assume that two patterns are expressed as AIFSs in $X=\left\{x_{1}, x_{2}, x_{3}\right\}$. They are given as:

$$
\begin{aligned}
& A_{1}=\left\{\left\langlex_{1}, 0.2,0.4>,\left\langle x_{2}, 0.1,0.4>,<x_{3}, 0.2,0.5>\right\},\right.\right. \\
& A_{2}=\left\{\left\langlex_{1}, 0.3,0.3>,\left\langle x_{2}, 0.2,0.3>,<x_{3}, 0.4,0.3>\right\} .\right.\right.
\end{aligned}
$$

A sample to be classified is given as AIFSs $B=\left\{\left\langle x_{1}, 0,0\right\rangle,\left\langle x_{2}, 0,0\right\rangle,\left\langle x_{3}, 0,0\right\rangle\right\}$.

Based on the distance measure developed from Vlachos and Sergiadis's [33] discrimination information, the following results can be derived:

$$
D_{V S}\left(A_{1}, B\right)=D_{V S}\left(A_{2}, B\right)=1.8 \ln 2 /(6 \ln 2)=0.3 \text {. }
$$

According to the proposed distance measure $D^{I}$, the distance degrees between $B$ and three patterns can be yielded as following:

$$
D^{I}\left(A_{1}, B\right)=0.2199, D^{I}\left(A_{2}, B\right)=0.1780 \text {. }
$$

These results indicate that the distance measures defined based on the discrimination information cannot be used to classify the sample $B$, since the similarity degree between $B$ and $A_{1}$ is identical to the similarity between $B$ and $A_{2}$. Although the given sample is hard to classify, we can see that it is closer to $A_{2}$ whose membership and non-membership grades have less difference. It is shown that the proposed distance measure $D^{I}$ can get $D^{I}\left(A_{2}, B\right)<D^{I}\left(A_{1}, B\right)$, which coincides with intuitive analysis. So the sample $\mathrm{B}$ should be classified as $A_{2}$ based on the minimum distance principle.

Example 8. There are two patterns expressed in forms of AIFSs over $X=\left\{x_{1}, x_{2}\right\}$. They are given as:

$$
\begin{gathered}
A_{1}=\left\{<x_{1}, 0.1,0.2>,<x_{2}, 0.1,0.7>\right\}, \\
A_{2}=\left\{<x_{1}, 0.3,0.4>,<x_{2}, 0.75,0.15>\right\} .
\end{gathered}
$$

A sample to be classifies is expressed as AIFSs $B=\left\{\left\langle x_{1}, 0.4,0.5\right\rangle,\left\langle x_{2}, 0.4,0.4\right\rangle\right\}$.

In the similarity $S_{D_{k}}^{\eta}$ with $\eta=1$ and $k=0.5$, we can get: $S_{D_{0.5}}^{1}\left(A_{1}, B\right)=S_{D_{0.5}}^{1}\left(A_{2}, B\right)=0.85$.

Based on the similarity $S_{F_{k, \lambda}}^{\eta}$ with $\eta=1$ and $k=\lambda=0.5$, we have: $S_{F_{0.5,0.5}}^{1}\left(A_{1}, B\right)=$ $S_{F_{0.5,0.5}}^{1}\left(A_{2}, B\right)=0.85$.

By the proposed distance measure $D^{I}$, we can get:

$$
D^{I}\left(A_{1}, B\right)=0.2366, D^{I}\left(A_{2}, B\right)=0.1796
$$

So the new developed distance measure $D^{I}$ can classify the sample as $A_{2}$. But the complex similarity measures with additional parameters cannot classify this sample to a specific pattern. 
Example 9. Two patterns are expressed in forms of AIFSs over $X=\left\{x_{1}, x_{2}\right\}$. They are denoted as:

$$
\begin{aligned}
& \left.A_{1}=\left\{<x_{1}, 0.1,0.3\right\rangle,<x_{2}, 0.3,0.3>\right\}, \\
& A_{2}=\left\{<x_{1}, 0.2,0.2>,<x_{2}, 0.4,0.2>\right\} .
\end{aligned}
$$

A sample to be classifies is expressed as AIFSs $B=\left\{<x_{1}, 0.4,0.4>,<x_{2}, 0.6,0.4>\right\}$.

According to the similarity developed from normalized Hamming distance measure $S_{X Y}$, we can obtain:

$$
S_{X Y}\left(A_{1}, B\right)=S_{X Y}\left(A_{2}, B\right)=0.5 .
$$

Based on the similarity $S_{G_{k, \lambda}}^{\eta}$ with $\eta=1$ and $k=\lambda=0.5$, we have: $S_{G_{0.5,0.5}}^{1}\left(A_{1}, B\right)=S_{G_{0.5,0.5}}^{1}\left(A_{2}, B\right)=0.8$. By the proposed distance measure $D^{I}$, we can derive:

$$
D^{I}\left(A_{1}, B\right)=0.1528, D^{I}\left(A_{2}, B\right)=0.1155
$$

We can see that the new developed distance measure $D^{I}$ can classify the sample as $A_{2}$. But the complex similarity measures $S_{G_{k, \lambda}}^{\eta}$ with additional parameters and the similarity measure developed from Hamming distance cannot classify this sample to a specific pattern.

It is indicated by above examples that the proposed distance measure can quantify the distance between AIFSs more effectively and rationally than some existing measures. The expression of $D^{I}$ shows that the difference between membership degree and non-membership degree, i.e., $\mu(x)-v(x)$, and the hesitance degree, used as $\mu(x)+v(x)=1-\pi(x)$, are considered in the definition of new distance measures. Moreover, their contribution degrees on the distance measure are different. So the proposed measure can measure the difference between AIFSs more effectively. In the following section, we will discuss its performance in the application of multi-attribute decision making (MADM) under intuitionistic fuzzy environment.

\section{Application to Multi-Attribute Decision Making}

Due to its great capability in modeling uncertain information, AIFS has been widely used to solve MADM problems in intuitionistic fuzzy environments. Many methods for MADM have been proposed based on AIFSs. In this section, we will propose a new intuitionistic fuzzy MADM method based on the technique for order preference by similarity to an ideal solution (TOPSIS) method [37] and the new proposed distance measure for AIFSs. The MADM problems under intuitionistic fuzzy condition can be described as following.

Let $X=\left\{x_{1}, x_{2}, \cdots, x_{m}\right\}$ be the set of all alternatives to be assessed. Let $A=\left\{a_{1}, a_{2}, \cdots, a_{n}\right\}$ be the set of attribute being considered in the assessment. The weighs of each attribute $a_{i}$ is $w_{i}$, where $0 \leq$ $w_{i} \leq 1, i=1,2, \cdots, n$, and $\sum_{i=1}^{n} w_{i}=1$. The decision matrix given by decision maker is presented as:

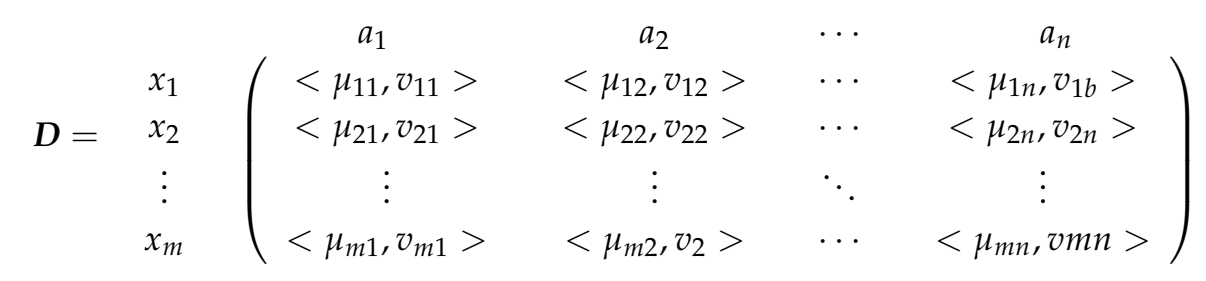

where $d_{i j}=<\mu_{i j}, v_{i j}>$ is the IFV denoting the evaluation information of alternative $x_{i}$ with respect to attribute $a_{j}$, with $i=1,2, \cdots, m$ and $j=1,2, \cdots, n$. The new method for MADM based on the proposed distance measure and TOPSIS method [37] can be depicted as following: 
Step 1. According to the partial order relation between IFVs, obtain the relative positive ideal solution $\alpha^{+}=\left(\alpha_{1}^{+}, \alpha_{2}^{+}, \cdots, \alpha_{n}^{+}\right)$of the attributes, where each relative value $\alpha_{j}^{+}$is calculated as:

$$
\alpha_{j}^{+}=\max _{i=1,2, \cdots, m}\left\{d_{i j}\right\}=<\max _{i=1,2, \cdots, m}\left\{\mu_{i j}\right\}, \min _{i=1,2, \cdots, m}\left\{v_{i j}\right\}>=<\mu_{j}^{+}, v_{j}^{+}>, j=1,2, \cdots, n .
$$

Similarly, get the relative negative ideal solution $\alpha^{-}=\left(\alpha_{1}^{-}, \alpha_{2}^{-}, \cdots, \alpha_{n}^{-}\right)$of the attributes, where each negative value $\alpha_{j}^{-}, j=1,2, \cdots, n$, is derived as:

$$
\alpha_{j}^{-}=\min _{i=1,2, \cdots, m}\left\{d_{i j}\right\}=<\min _{i=1,2, \cdots, m}\left\{\mu_{i j}\right\}, \max _{i=1,2, \cdots, m}\left\{v_{i j}\right\}>=<\mu_{j}^{-}, v_{j}^{-}>
$$

Step 2. Utilize the distance measure of IFVs defined in Equation (34) to calculate the similarity degree between the evaluating result $d_{i j}=<\mu_{i j}, v_{i j}>$ of alternative $x_{i}$ with respect to attribute $a_{j}$ and the relative positive ideal value $\alpha_{j}^{+}$of attribute $a_{j}$, with $i=1,2, \cdots, m$ and $j=1,2, \cdots, n$. Construct the positive similarity matrix $G^{+}=\left(g_{i j}^{+}\right)_{m \times n}$. The similarity degree is expressed as:

$$
g_{i j}^{+}=1-D^{I}\left(d_{i j}, \alpha_{j}^{+}\right)=1-\sqrt{\left(\frac{\mu_{i j}-v_{i j}}{2}-\frac{\mu_{j}^{+}-v_{j}^{+}}{2}\right)^{2}+\frac{1}{3}\left(\frac{\mu_{i j}+v_{i j}}{2}-\frac{\mu_{j}^{+}+v_{j}^{+}}{2}\right)^{2}}
$$

Step 3. Appling the distance measure of IFVs defined in Equation (34) to calculate the similarity degree between the evaluating result $d_{i j}=<\mu_{i j}, v_{i j}>$ of alternative $x_{i}$ respect to attribute $a_{j}$ and the relative negative ideal value $\alpha_{j}^{-}$of attribute $a_{j}$, with $i=1,2, \cdots, m$ and $j=1,2, \cdots, n$. Construct the negative similarity matrix $G^{-}=\left(g_{i j}^{-}\right)_{m \times n}$. The similarity degree is expressed as:

$$
g_{i j}^{-}=1-D^{I}\left(d_{i j}, \alpha_{j}^{-}\right)=1-\sqrt{\left(\frac{\mu_{i j}-v_{i j}}{2}-\frac{\mu_{j}^{-}-v_{j}^{-}}{2}\right)^{2}+\frac{1}{3}\left(\frac{\mu_{i j}+v_{i j}}{2}-\frac{\mu_{j}^{-}+v_{j}^{-}}{2}\right)^{2}}
$$

Step 4. Based on the attribute weights $w_{i}$ and the distance matrices $G^{+}$and $G^{-}$, calculate the weighted positive score $S^{+}\left(x_{i}\right)$ and weighted negative score $S^{-}\left(x_{i}\right)$ for each alternative $x_{i}$, respectively, $i=1,2, \cdots, m$. The positive and negative scores are calculated as: $S^{+}\left(x_{i}\right)=\sum_{j=1}^{n} w_{j} g_{i j}^{+}$and $S^{-}\left(x_{i}\right)=$ $\sum_{j=1}^{n} w_{j} g_{i j}^{-}$.

Step 5. Obtain the relative closeness degree $T\left(x_{i}\right)$ of each alternative $x_{i}$ as: $T\left(x_{i}\right)=$ $S^{+}\left(x_{i}\right) /\left(S^{+}\left(x_{i}\right)+S^{-}\left(x_{i}\right)\right), i=1,2, \cdots, m$.

Step 6. Get the preference order of all alternatives by the comparing their relative closeness degree. Larger closeness degree indicates better preference order.

Then, several examples will be used to show the implementation of the proposed MADM method. Comparative analysis based on the results obtained by the proposed method and some existing methods [38-40] will also be presented.

Example 10. An investment company want to invest some money to a project. There are five alternatives of companies to be assessed by an investment company. The decision maker evaluates these companies with respect to four attributes to get the best option. Five alternative companies are given as: (1) $x_{1}$ : the food company; (2) $x_{2}$ : the chemical company; (3) $x_{3}$ : the car company; (4) $x_{4}$ : the computer company; (5) $x_{5}$ : the furniture company. For attributes to be accounted are: (1) $a_{1}$ : the benefit rate; (2) $a_{2}$ : the risk of investment; (3) $a_{3}$ : the difficulty of investment; and (4) $a_{4}$ : the influence on environment. The attribute weights of $a_{1}, a_{2}, a_{3}$ and $a_{4}$ are $0.25,0.4$, 0.2 and 0.15 , respectively, i.e., $w_{1}=0.25, w_{2}=0.4, w_{3}=0.2$, and $w_{4}=0.15$. The decision matrix provided by decision maker is: 


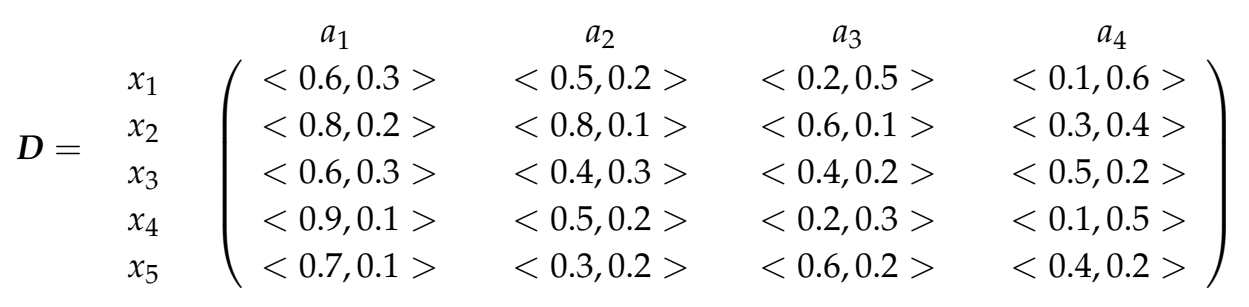

This problem can be solved by the following steps:

(1) Comparing the IFVs in each column, we can get the relative positive and negative ideal solutions as:

$$
\begin{aligned}
& \alpha_{1}^{+}=<0.9,0.1>, \alpha_{2}^{+}=<0.8,0.1>, \alpha_{3}^{+}=<0.6,0.1>, \alpha_{4}^{+}=<0.5,0.2>; \\
& \alpha_{1}^{-}=<0.6,0.3>, \alpha_{2}^{-}=<0.3,0.3>, \alpha_{3}^{-}=<0.2,0.5>, \alpha_{4}^{-}=<0.1,0.6>
\end{aligned}
$$

(2) Based on the distance measure $D^{I}$ defined in Equation (39), the positive similarity matrix can be constructed as:

$$
G^{+}=\left(\begin{array}{cccc}
0.7483 & 0.7918 & 0.6000 & 0.6000 \\
0.9000 & 1.0000 & 1.0000 & 0.8000 \\
0.7483 & 0.6945 & 0.8472 & 1.0000 \\
1.0000 & 0.7918 & 0.6945 & 0.6488 \\
0.8845 & 0.6785 & 0.9243 & 0.9243
\end{array}\right)
$$

(3) Using the distance measure $D^{I}$ of IFVs and the expression in Equation (40), we can get the negative similarity matrix as:

$$
G^{-}=\left(\begin{array}{cccc}
1.0000 & 0.8472 & 1.0000 & 1.0000 \\
0.8472 & 0.6394 & 0.6000 & 0.8000 \\
1.0000 & 0.9423 & 0.7483 & 0.6000 \\
0.7483 & 0.8472 & 0.8845 & 0.9423 \\
0.8472 & 0.9423 & 0.6488 & 0.6488
\end{array}\right)
$$

(4) According to the attribute weights, we can get the weighted positive scores of all alternatives as:

$$
S^{+}\left(x_{1}\right)=0.7138, S^{+}\left(x_{2}\right)=0.9450, S^{+}\left(x_{3}\right)=0.7834, S^{+}\left(x_{4}\right)=0.8030, S^{+}\left(x_{5}\right)=0.8223 .
$$

The weighted negative scores of all alternatives can be obtained as:

$$
S^{-}\left(x_{1}\right)=0.9389, S^{-}\left(x_{2}\right)=0.7076, S^{-}\left(x_{3}\right)=0.8666, S^{-}\left(x_{4}\right)=0.8442, S^{-}\left(x_{5}\right)=0.8158 .
$$

(5) The relative closeness degree of each alternative can be calculated as:

$$
T\left(x_{1}\right)=0.4319, T\left(x_{2}\right)=0.5718, T\left(x_{3}\right)=0.4751, T\left(x_{4}\right)=0.4875, T\left(x_{5}\right)=0.5020 .
$$

(6) Since $T\left(x_{2}\right)>T\left(x_{5}\right)>\left(x_{4}\right)>T\left(x_{3}\right)>T\left(x_{1}\right)$, we can rank five alternatives $x_{1}, x_{2}, x_{3}, x_{4}$ and $x_{5}$ in the preference order: $x_{2} \succ x_{5} \succ x_{4} \succ x_{3} \succ x_{1}$.

Comparing with the results obtained by the methods proposed in [38-40], we can find that the ranking preference orders obtained based on the TOPSIS method and the proposed distance measure is identical to the orders yielded by Joshi and Kumar's method [38], Wu and Chen's method with $w_{q}=1, w_{q^{\prime}}=2 / 3, w_{q^{\prime \prime}}=1 / 3, w_{a}=1, w_{a^{\prime}}=2 / 3, w_{a^{\prime \prime}}=1 / 3$ [39], and the method proposed by Chen, Chen and Lan [40]. This example indicates that the proposed method is capable to solve 
MADM problems in intuitionistic fuzzy environment. It can yield reasonable preference order as existing methods.

Example 11. Five vice presidents of a university will be assessed to run for the president of the university. These five candidates are denoted by alternatives $x_{1}, x_{2}, x_{3}, x_{4}$ and $x_{5}$. They will be assessed from four aspects, namely, work performance, academic performance, leadership, and personality, which are denoted by four attributes $a_{1}, a_{2}, a_{3}$ and $a_{4}$, respectively. The weights of $a_{1}, a_{2}, a_{3}$ and $a_{4}$ are $0.1,0.2,0.3$ and 0.4 , respectively. So we have $w_{1}=0.1, w_{2}=0.2$. $w_{3}=0.3$ and $w_{4}=0.4$. The decision matrix expressed by IFVs is shown as following:

$$
\left.\boldsymbol{D}=\begin{array}{ccccc}
a_{1} & a_{2} & a_{3} & a_{4} \\
x_{1} & <0.4,0.5> & <0.3,0.6> & <0.4,0.4> & <0.5,0.3> \\
x_{2} & <0.4,0.4> & <0.5,0.4> & <0.3,0.5> & <0.3,0.4> \\
x_{3} & <0.4,0.6> & <0.5,0.5> & <0.4,0.6> & <0.4,0.6> \\
x_{4} & <0.3,0.4> & <0.2,0.6> & <0.1,0.9> & <0.4,0.4> \\
x_{5} & <0.5,0.4> & <0.3,0.6> & <0.3,0.5> & <0.47,0.5>
\end{array}\right)
$$

(1) Based on the partial order relation between IFVs, the relative positive and negative ideal solutions of each attribute can be get as:

$$
\begin{aligned}
& \alpha_{1}^{+}=<0.5,0.4>, \alpha_{2}^{+}=<0.5,0.4>, \alpha_{3}^{+}=<0.4,0.4>, \alpha_{4}^{+}=<0.5,0.3> \\
& \alpha_{1}^{-}=<0.3,0.6>, \alpha_{2}^{-}=<0.2,0.6>, \alpha_{3}^{-}=<0.1,0.9>, \alpha_{4}^{-}=<0.3,0.6>
\end{aligned}
$$

(2) We can get the positive similarity matrix according to the proposed distance measures:

$$
G^{+}=\left(\begin{array}{cccc}
0.9000 & 0.8000 & 1.0000 & 1.0000 \\
0.9423 & 1.0000 & 0.9000 & 0.8472 \\
0.8472 & 0.9423 & 0.8845 & 0.7918 \\
0.8845 & 0.7483 & 0.5959 & 0.9000 \\
1.0000 & 0.8000 & 0.9000 & 0.8750
\end{array}\right)
$$

(3) The negative similarity matrix can be obtained based on the proposed distance measure $D^{I}$ of IFVs and the expression in Equation (40).

$$
G^{-}=\left(\begin{array}{llll}
0.9000 & 0.9423 & 0.5959 & 0.7483 \\
0.8472 & 0.7483 & 0.6945 & 0.8845 \\
0.9423 & 0.7918 & 0.7000 & 0.9423 \\
0.8845 & 1.0000 & 1.0000 & 0.8472 \\
0.8000 & 0.9423 & 0.6945 & 0.8635
\end{array}\right)
$$

(4) According to the attribute weights $w_{1}=0.1, w_{2}=0.2$. $w_{3}=0.3$ and $w_{4}=0.4$, we can get the weighted positive scores of all alternatives as:

$$
S^{+}\left(x_{1}\right)=0.9500, S^{+}\left(x_{2}\right)=0.9031, S^{+}\left(x_{3}\right)=0.8553, S^{+}\left(x_{4}\right)=0.7769, S^{+}\left(x_{5}\right)=0.8800 .
$$

The weighted negative scores of all alternatives can be obtained as:

$$
S^{-}\left(x_{1}\right)=0.7565, S^{-}\left(x_{2}\right)=0.7966, S^{-}\left(x_{3}\right)=0.8395, S^{-}\left(x_{4}\right)=0.9274, S^{-}\left(x_{5}\right)=0.8222 .
$$

(5) The relative closeness degree of each alternative can be calculated as:

$$
T\left(x_{1}\right)=0.5567, T\left(x_{2}\right)=0.5314, T\left(x_{3}\right)=0.5047, T\left(x_{4}\right)=0.4559, T\left(x_{5}\right)=0.5170 .
$$


(6) Since $T\left(x_{1}\right)>T\left(x_{2}\right)>\left(x_{5}\right)>T\left(x_{3}\right)>T\left(x_{4}\right)$, we can rank five alternatives $x_{1}, x_{2}, x_{3}, x_{4}$ and $x_{5}$ in the preference order: $x_{1} \succ x_{2} \succ x_{5} \succ x_{3} \succ x_{4}$.

By the methods proposed in Reference [38] and Reference [40], we can also solve this problem. The preference orders obtained by the methods in Reference [38] and Reference [40] are $x_{1} \succ x_{2} \succ$ $x_{5} \succ x_{3} \succ x_{4}$, which is identical to the preference order obtained by our proposed method. But the method proposed by Wu and Chen [39] cannot be used to solve this problem due the problem of "division by zero". This example shows that the proposed method can overcome the drawback of Wu and Chen's method [39]. The proposed method performs as well as the method proposed by Joshi and Kumar [38], and the method proposed by Chen, Chen and Lan [40].

Above examples demonstrate that the proposed distance measure can be applied into the problem of MADM under intuitionistic fuzzy environment. The developed MADM method based on the TOPSIS method and the proposed distance measure $D^{I}$ performs as well as existing methods in Reference [38] and Reference [40], which are also developed based on the TOPSIS method. However, we note that the distance measure used in Reference [38] is defined based on the Hausdorff metric, which has weaker discrimination ability. Moreover, Joshi and Kumar's [38] method will also be troubled by the problem of "division by zero". The method proposed in [40] is also an effective method for solving MADM in intuitionistic fuzzy environment. But the similarity measure used in Reference [40] is developed based on the right-angled triangular fuzzy numbers [28], which is more complex than the proposed distance measure. So the MADM method based on the proposed distance method and the TOPSIS method is much easier to implement with less computation complexity.

\section{Conclusions}

Even though many distance and similarity measures have been introduced for AIFSs, an effective intuitionistic fuzzy distance measure with concise form and specific physical meaning is still desirable. In this paper, we have proposed a new distance measure based on the relation between AIFSs and interval values. It was proved that the proposed distance measure satisfies all properties in the axiomatic definition of distance measure. Numerical examples indicated that the new distance measure can overcome the drawbacks of existing measures. So it has greater discrimination ability and outperforms other existing measures. Moreover, we investigated the application of the new distance measure in MADM under intuitionistic fuzzy condition. A new MADM method was developed based on the TOPSIS method and the proposed distance measure. Two application examples were applied to show the implementation and performance of the developed MADM method. It was shown that the proposed MADM method can get identical preference orders as other methods. The proposed MADM method can also overcome the drawbacks in some existing methods. This demonstrates that the new distance measure can be effectively used in the real application of MADM. In a further study, we will investigate the potential application of the proposed MADM method in areas such as economic management, ecological evaluation, military assessment, and so on.

Author Contributions: Conceptualization, Y.S. and D.K.; methodology, Y.S.; validation, W.Q.; Y.Y. and Z.Z.; writing-original draft preparation, D.K.; writing-review and editing, W.Q.; funding acquisition, Y.S.

Funding: This research was funded by National Natural Science Foundation of China under Grants No. 61703426, No. 61273275, No. 61806219, No. 61876189 and No. 61503407.

Conflicts of Interest: The authors declare no conflict of interest.

\section{References}

1. Zadeh, L.A. Fuzzy sets. Inf. Control. 1965, 8, 338-353. [CrossRef]

2. Atanassov, K. Intuitionistic fuzzy sets. Fuzzy Sets. Syst. 1986, 20, 87-96. [CrossRef]

3. Gau, W.L.; Buehrer, D.J. Vague sets. IEEE Trans. Syst. Man Cybern. 1993, 23, 610-614. [CrossRef]

4. Bustince, H.; Burillo, P. Vague sets are intuitionistic fuzzy sets. Fuzzy Sets. Syst. 1996, 79, 403-405. [CrossRef] 
5. Fan, C.; Song, Y.; Fu, Q.; Lei, L.; Wang, X. New operators for aggregating intuitionistic fuzzy information with their application in decision making. IEEE Access. 2018, 6, 27214-27238. [CrossRef]

6. Song, Y.; Wang, X.; Lei, L.; Xue, A. A novel similarity measure on intuitionistic fuzzy sets with its applications. Appl. Intell. 2015, 42, 252-261. [CrossRef]

7. Song, Y.; Wang, X.; Quan, W.; Huang, W. A new approach to construct similarity measure for intuitionistic fuzzy sets. Soft Comput. 2017, 1-14. [CrossRef]

8. Wang, X.; Song, Y. Uncertainty measure in evidence theory with its applications. Appl. Intell. 2018, 48, 1672-1688. [CrossRef]

9. Song, Y.; Wang, X.; Zhu, J.; Lei, L. Sensor dynamic reliability evaluation based on evidence and intuitionistic fuzzy sets. Appl. Intell. 2018, 1-13. [CrossRef]

10. Fan, C.; Song, Y.; Lei, L.; Wang, X.; Bai, S. Evidence reasoning for temporal uncertain information based on relative reliability evaluation. Exp. Syst. Appl. 2018, 113, 264-276. [CrossRef]

11. Szmidt, E.; Kacprzyk, J. Distances between intuitionistic fuzzy sets. Fuzzy Sets. Syst. 1997, 114, 505-518. [CrossRef]

12. Vlachos, K.I.; Sergiadis, G.D. Intuitionistic fuzzy information-applications to pattern recognition. Pattern Recognit. Lett. 2007, 28, 197-206. [CrossRef]

13. Wang, W.; Xin, X. Distance measure between intuitionistic fuzzy sets. Pattern Recognit. Lett. 2005, 26, 2063-2069. [CrossRef]

14. Li, D.; Cheng, C. New similarity measures of intuitionistic fuzzy sets and application to pattern recognition. Pattern Recognit. Lett. 2002, 23, 221-225. [CrossRef]

15. Mitchell, H.B. On the Dengfeng-Chuntian similarity measure and its application to pattern recognition. Pattern Recognit. Lett. 2003, 24, 3101-3104. [CrossRef]

16. Liang, Z.; Shi, P. Similarity measures on intuitionistic fuzzy sets. Pattern Recognit. Lett. 2003, 24, $2687-2693$. [CrossRef]

17. Hung, W.L.; Yang, M.S. On similarity measures between intuitionistic fuzzy sets. Int. J. Intell. Syst. 2008, 23, 364-383. [CrossRef]

18. Xu, Z.S.; Chen, J. An overview of distance and similarity measures of intuitionistic fuzzy sets. Int. J. Uncertain. Fuzz. Knowl.-Based Syst. 2008, 16, 529-555. [CrossRef]

19. Szmidt, E.; Kacprzyk, J. A similarity measure for intuitionistic fuzzy sets and its application in supporting medical diagnostic reasoning. In Proceedings of the 7th International Conference on Artificial Intelligence and Soft Computing (ICAISC 2004), Zokopane, Poland, 7-11 June 2004; pp. 388-393.

20. $\mathrm{Xu}, \mathrm{Z} . S$.; Yager, R.R. Intuitionistic and interval-valued intuitionistic fuzzy preference relations and their measures of similarity for the evaluation of agreement within a group. Fuzzy Optim. Decis. Mak. 2009, 8, 123-139. [CrossRef]

21. Xia, M.M.; Xu, Z.S. Some new similarity measures for intuitionistic fuzzy values and their application in group decision making. J. Syst. Sci. Syst. Eng. 2010, 19, 430-452. [CrossRef]

22. Wei, C.P.; Wang, P.; Zhang, Y.Z. Entropy, similarity measure of interval-valued intuitionistic fuzzy sets and their applications. Inf. Sci. 2011, 18, 4273-4286. [CrossRef]

23. Ye, J. Cosine similarity measures for intuitionistic fuzzy sets and their applications. Math. Comput. Model. 2011, 53, 91-97. [CrossRef]

24. Hwang, C.M.; Yang, M.S.; Hung, W.L.; Lee, M.G. A similarity measure of intuitionistic fuzzy sets based on the Sugeno integral with its application to pattern recognition. Inf. Sci. 2012, 189, 93-109. [CrossRef]

25. Li, J.Q.; Deng, G.N.; Li, H.X.; Zeng, W.Y. The relationship between similarity measure and entropy of intuitionistic fuzzy sets. Inf. Sci. 2012, 188, 314-321. [CrossRef]

26. Zhang, H.; Yu, L. New distance measures between intuitionistic fuzzy sets and interval-valued fuzzy sets. Inf. Sci. 2013, 245, 181-196. [CrossRef]

27. Boran, F.E.; Akay, D. A biparametric similarity measure on intuitionistic fuzzy sets with applications to pattern recognition. Inf. Sci. 2014, 255, 45-57. [CrossRef]

28. Chen, S.M.; Cheng, S.H.; Lan, T.C. A novel similarity measure between intuitionistic fuzzy sets based on the centroid points of transformed fuzzy numbers with applications to pattern recognition. Inf. Sci. 2016, 343, 15-40. [CrossRef]

29. Atanassov, K.; Gargov, G. Interval-valued intuitionistic fuzzy sets. Fuzzy Sets Syst. 1989, 31, $343-349$. [CrossRef] 
30. Chen, S.M.; Tan, J.M. Handling multicriteria fuzzy decision making problems based on vague set theory. Fuzzy Sets Syst. 1994, 67, 163-172. [CrossRef]

31. Hong, D.H.; Choi, C.H. Multicriteria fuzzy decision-making problems based on vague set theory. Fuzzy Sets Syst. 2000, 114, 103-113. [CrossRef]

32. Xu, Z.S.; Yager, R.R. Some geometric aggregation operators based on intuitionistic fuzzy sets. Int. J. Gen. Syst. 2006, 35, 417-433. [CrossRef]

33. $\mathrm{Xu}, \mathrm{Z}$.S. Some similarity measures of intuitionistic fuzzy sets and their applications to multiple attribute decision making. Fuzzy Optim. Decis. Mak. 2007, 6, 109-121. [CrossRef]

34. Hong, D.H.; Kim, C. A note on similarity measures between vague sets and between elements. Inf. Sci. 1999, 115, 83-96. [CrossRef]

35. Irpino, A.; Verde, R. Dynamic clustering of interval data using a Wasserstein-based distance. Pattern Recognit. Lett. 2008, 29, 1648-1658. [CrossRef]

36. Tran, L.; Duckstein, L. Comparison of fuzzy numbers using a fuzzy distance measure. Fuzzy Sets Syst. 2002, 130, 331-341. [CrossRef]

37. Lai, Y.J.; Liu, T.Y.; Hwang, C.L. TOPSIS for MODM. Eur. J. Oper. Res. 1994, 76, 486-500. [CrossRef]

38. Joshi, D.; Kumar, S. Intuitionistic fuzzy entropy and distance measure based on TOPSIS method for multi-criteria decision making. Egypt. Inf. J. 2014, 15, 97-104. [CrossRef]

39. Wu, M.C.; Chen, T.Y. The ELECTRE multicriteria analysis approach based on Atanassov's intuitionistic fuzzy sets. Expert Syst. Appl. 2011, 38, 12318-12327. [CrossRef]

40. Chen, S.M.; Cheng, S.H.; Lan, T.C. Multicriteria decision making based on the TOPSIS method and similarity measures between intuitionistic fuzzy values. Inf. Sci. 2016, 367, 279-295. [CrossRef]

(C) 2018 by the authors. Licensee MDPI, Basel, Switzerland. This article is an open access article distributed under the terms and conditions of the Creative Commons Attribution (CC BY) license (http:/ / creativecommons.org/licenses/by/4.0/). 